\title{
Analysis and prediction of dimensions and cost of laser micro-machining internal channel fabrication process
}

\author{
S. M. Karazi ${ }^{1, a}$ and D. Brabazon ${ }^{1}$ \\ ${ }^{1}$ School of Mechanical and Manufacturing Engineering, Dublin City University, Dublin, Ireland
}

\begin{abstract}
This paper presents the utilisation of Response Surface Methodology (RSM) as the prediction tool for the laser micro-machining process. Laser internal microchannels machined using pulsed $\mathrm{Nd}: \mathrm{YVO}_{4}$ laser in polycarbonate were investigated. The experiments were carried out according to $3^{3}$ factorial Design of Experiment (DoE). In this work the three input process set as control parameters were laser power, P; pulse repetition frequency, PRF; and sample translation speed, U. Measured responses were the channel width and the micro-machining operating cost per metre of produced microchannels. The responses were sufficiently predicted within the set micro-machining parameters limits. Two factorial interaction (2FI) and quadratic polynomial regression equations for both responses were constructed. It is proposed that the developed prediction equations can be used to find locally optimal micro-machining process parameters under experimental and operational conditions.
\end{abstract}

\section{Introduction}

Laser micro-machining is a materials-processing technique that employs lasers to induce managed vaporisation to provide required micro-scale geometrical shape and dimensional ablations. Despite the fact that laser micro-machining is a technically complicated manufacturing process, research work has allowed the fabrication of precise, smooth, and clean components at high speed [1-3]. Laser micro-machining is employed for many micro-machining applications in the fields of telecommunications, glass cutting, micro-sensors [4-6]; micro-via, ink jet printer nozzles, biomedical catheter drilling, thin-film scribing [7]; micro-fluidic channels for blood/protein analysis [8]; optical vibration sensors [9]; three-dimensional binary data storage [10-12]; and novelty fabrications [13].

In order to find a set of laser processing parameters that supplies the preferred micro-channel dimensions for a certain application under specific processing constraints, predictive models can be utilised. Several statistical and numerical approaches have been used to predict and optimise various laser manufacturing processes including design of experiments, Artificial Neural Networks (ANN), genetic algorithms, finite elements analysis, ant colony optimisation, and fuzzy logic [3, 14-15].

The prediction of the dimensions of the laser micro-machining channels is an important requirement for selection of appropriate laser control parameters. Based on the intensity range used in the experimental work presented in this paper, the induced laser absorption is physically characterised as laser supported combustion type. Energy is deposited into the material by the laser

a e-mail: shadi.karazi@dcu.ie

This is an Open Access article distributed under the terms of the Creative Commons Attribution-Noncommercial License 3.0, which permits unrestricted use, distribution, and reproduction in any noncommercial medium, provided the original work is properly cited. 
pulse and is transported out of the irradiated region by reflection and thermal diffusion. In this case, the relative rate of energy absorbed and thermal diffusion determines the damage threshold. Dependence of the breakdown threshold on the presence of impurity electrons in the conduction band makes the threshold for optical breakdown non-deterministic [16]. Plasma is initiated at the target's surface where the temperature can exceed $10^{4} \mathrm{~K}$ during the ablative interaction [17]. All of these factors combine to make it difficult to produce models which accurately predict the geometry of channels produced during the laser micro-machining process.

Normally coarse or fine tuning of the laser machining process input parameters is used to produce micro-channels with a predetermined specification. Even though, this is usually carried out by specially qualified personnel, the parameter selection process is time consuming as it is usually implemented via a trial and error method. Since the laser micro-machining process is affected by several parameters, this classic parameter selection process is non-systematic and usually does not produce an optimised combination of process parameters, which can be used to attain the required outcomes. Using a systematic study, such as Response Surface Methodology (RSM), allows for estimation of the interactive effects of the process input parameters on the responses [18]. This work aims to use RSM to develop mathematical models for the laser machined micro-channel width and the micro-machining operating cost in terms of the laser micro-machining input parameters.

Design of Experiments (DoE) models that were developed and implemented are presented below. These models relate the input laser processing parameters namely: power, pulse repetition frequency and translation speed, to the output responses namely: the width and the micro-machining operating cost per metre of developed micro-channels. These models may be used to select the input parameters for required output dimensions and to evaluate process cost in advance of contracted work initiation.

\section{Experimental set-up}

\subsection{Experimental work}

The laser system used for micro-machining in this work was a $\mathrm{Nd}: \mathrm{YVO}_{4}$ laser with $2 \mathrm{~W}$ maximum power and $1064 \mathrm{~nm}$ wavelength. Micro-channels were produced in polycarbonate sheet of $10 \mathrm{~mm}$ thickness. Since the width measurement was going to be done using an OMNIMET optical microscope, the distance between each two micro-channels was set as $2 \mathrm{~mm}$. The polycarbonate sample position was set at the start of each experiment such that its back surface plane was coincident with the focal plane of the laser. This enabled the laser micro-machining process to be started with the laser spot on the back surface of the polycarbonate sheet. The polycarbonate sheet work piece was mounted on the $3 \mathrm{D}$ positioning stage and then moved along the $\mathrm{X}$ axis away from the laser source, thus creating the micro-channel from the back to the front of the sample. Fig. 1 shows optical components setup and the work piece.

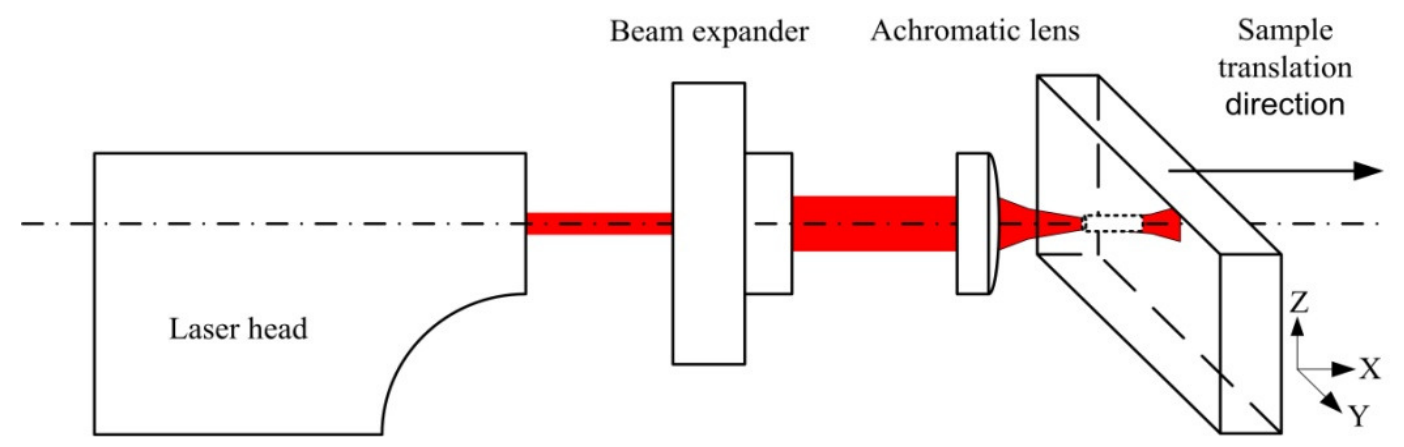

Fig. 1: Laser micro-machining optical components arrangement. 


\subsection{Experimental design}

A series of experiments were designed to determine the relationship between the main laser process parameters of a Nd: $\mathrm{YVO}_{4}$ laser and the machining process cost and the dimensions of corresponding produced micro-channels. After initial screening experiments, a factorial design of experiments was carried out using Design-Expert software. The three process parameters analysed in this work were the laser power, pulse repetition frequency and translation speed of the processed sample. Each of these were analysed at three levels in the form of a $3^{3}$ factorial design of experiments. The low, middle and high levels were chosen for power, pulse repetition frequency and translation speed. The low level is represented by -1 , the middle by 0 and the high level by 1 . Table 1 shows laser input parameters and the actual and coded experimental design levels used.

Table 1: Control parameters levels and their corresponding DoE coding.

\begin{tabular}{c|ccc|ccc}
\hline Variables & \multicolumn{3}{|c|}{ Actual } & \multicolumn{3}{c}{ Coded } \\
& Low & Mid & High & Low & Mid & High \\
\hline P $(\mathbf{W})$ & 0.5 & 1.0 & 1.5 & -1 & 0 & 1 \\
PRF $(\mathbf{k H z})$ & 13 & 23 & 33 & -1 & 0 & 1 \\
$\mathbf{U}(\mathbf{m m} / \mathbf{s e c})$ & 0.50 & 1.74 & 2.98 & -1 & 0 & 1 \\
\hline
\end{tabular}

There are 27 possible combinations of the three process parameters at the three levels. Table 2 shows a list of these 32 combinations of the laser control parameters that were used in the conducted experiments.

Table 2: List of laser control parameter of the experiments performed.

\begin{tabular}{lllll|lllll}
$\begin{array}{l}\text { Exp. } \\
\text { No. }\end{array}$ & $\begin{array}{l}\text { Run } \\
\text { order }\end{array}$ & $\begin{array}{l}\mathbf{P} \\
(\mathbf{W})\end{array}$ & $\begin{array}{l}\text { PRF } \\
(\mathbf{k H z})\end{array}$ & $\begin{array}{l}\mathbf{U} \\
(\mathbf{m m} / \mathbf{s e c})\end{array}$ & $\begin{array}{l}\text { Exp. } \\
\text { No. }\end{array}$ & $\begin{array}{l}\text { Run } \\
\text { order }\end{array}$ & $\begin{array}{l}\mathbf{P} \\
(\mathbf{W})\end{array}$ & $\begin{array}{l}\text { PRF } \\
(\mathbf{k H z})\end{array}$ & $\begin{array}{l}\mathbf{U} \\
(\mathbf{m m} / \mathbf{s e c})\end{array}$ \\
\hline $\mathbf{1}$ & $\mathbf{2 3}$ & 0.5 & 13 & 0.5 & $\mathbf{1 7}$ & $\mathbf{1}$ & 1 & 33 & 1.74 \\
$\mathbf{2}$ & $\mathbf{1 5}$ & 1 & 13 & 0.5 & $\mathbf{1 8}$ & $\mathbf{1 6}$ & 1.5 & 33 & 1.74 \\
$\mathbf{3}$ & $\mathbf{1 1}$ & 1.5 & 13 & 0.5 & $\mathbf{1 9}$ & $\mathbf{4}$ & 0.5 & 13 & 2.98 \\
$\mathbf{4}$ & $\mathbf{2 0}$ & 0.5 & 23 & 0.5 & $\mathbf{2 0}$ & $\mathbf{9}$ & 1 & 13 & 2.98 \\
$\mathbf{5}$ & $\mathbf{1 4}$ & 1 & 23 & 0.5 & $\mathbf{2 1}$ & $\mathbf{8}$ & 1.5 & 13 & 2.98 \\
$\mathbf{6}$ & $\mathbf{3 2}$ & 1.5 & 23 & 0.5 & $\mathbf{2 2}$ & $\mathbf{7}$ & 0.5 & 23 & 2.98 \\
$\mathbf{7}$ & $\mathbf{2}$ & 0.5 & 33 & 0.5 & $\mathbf{2 3}$ & $\mathbf{2 1}$ & 1 & 23 & 2.98 \\
$\mathbf{8}$ & $\mathbf{1 7}$ & 1 & 33 & 0.5 & $\mathbf{2 4}$ & $\mathbf{1 2}$ & 1.5 & 23 & 2.98 \\
$\mathbf{9}$ & $\mathbf{2 8}$ & 1.5 & 33 & 0.5 & $\mathbf{2 5}$ & $\mathbf{2 7}$ & 0.5 & 33 & 2.98 \\
$\mathbf{1 0}$ & $\mathbf{2 4}$ & 0.5 & 13 & 1.74 & $\mathbf{2 6}$ & $\mathbf{1 0}$ & 1 & 33 & 2.98 \\
$\mathbf{1 1}$ & $\mathbf{2 2}$ & 1 & 13 & 1.74 & $\mathbf{2 7}$ & $\mathbf{2 6}$ & 1.5 & 33 & 2.98 \\
$\mathbf{1 2}$ & $\mathbf{3 0}$ & 1.5 & 13 & 1.74 & $\mathbf{2 8}$ & $\mathbf{6}$ & 1 & 23 & 1.74 \\
$\mathbf{1 3}$ & $\mathbf{3}$ & 0.5 & 23 & 1.74 & $\mathbf{2 9}$ & $\mathbf{3 1}$ & 1 & 23 & 1.74 \\
$\mathbf{1 4}$ & $\mathbf{1 8}$ & 1 & 23 & 1.74 & $\mathbf{3 0}$ & $\mathbf{1 3}$ & 1 & 23 & 1.74 \\
$\mathbf{1 5}$ & $\mathbf{5}$ & 1.5 & 23 & 1.74 & $\mathbf{3 1}$ & $\mathbf{2 5}$ & 1 & 23 & 1.74 \\
$\mathbf{1 6}$ & $\mathbf{2 9}$ & 0.5 & 33 & 1.74 & $\mathbf{3 2}$ & $\mathbf{1 9}$ & 1 & 23 & 1.74 \\
\hline
\end{tabular}

For variability analysis, five additional experiments were repeated at the middle point of the investigated ranges, such that the total number of experiments conducted was $32\left(=3^{3}+5\right)$. Fig. 2 shows the distribution of process control parameters investigated. 


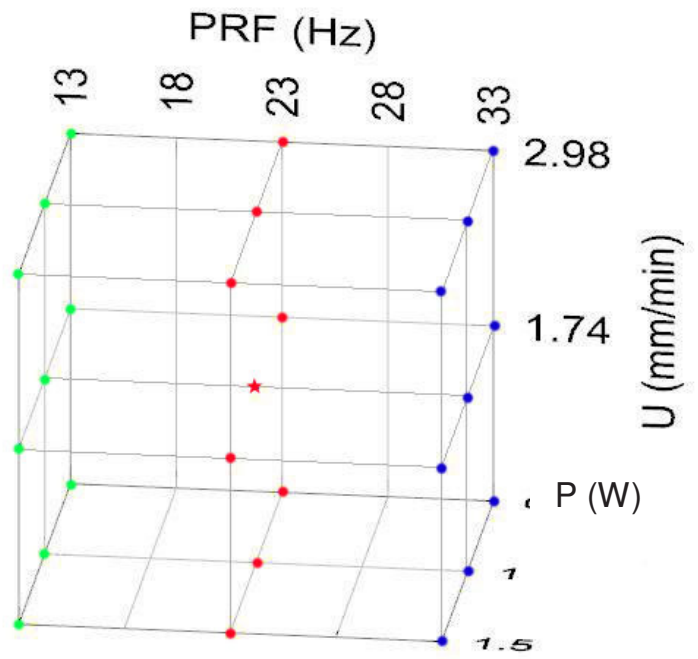

Fig. 2: 3D representation of the process control parameters' points investigated.

indicates mid-point where five additional experiments were repeated.

\subsection{Micro-machining cost calculation}

Laser of micro-machining processing cost can be roughly evaluated as micro-machining cost per length or per time for a specific laser micro-machining operation. Unplanned breakdown and maintenance have not been taken into account while estimating the operating cost. Since this laser was for experimental purposes labour cost was not considered however, it should be considered when dealing with operational system.

Assuming that electrical consumption of the laser power supply is linearly proportional to the laser power emitted by the laser head, the total approximated operating cost per hour as a function of the output power can be estimated by $1.4723+0.064 \times \mathrm{P}$. Table 3 shows a breakdown of estimated micro-machining cost per hour. The total approximated operating cost per unit length (in $€ / \mathrm{m}$ ) of the weld is given by Equation (1), assuming $85 \%$ utilisation.

Table 3: Breakdown of estimated micro-machining cost per hour.

\begin{tabular}{lll}
\hline Element of cost & Calculations & Cost $€ / \mathbf{h r}$ \\
\hline Laser power supply & $(800 \mathrm{~W})(€ 0.16 / \mathrm{kW} \mathrm{hr})(\mathrm{P} / 2) / 1000$ & $0.064 \times \mathrm{P}$ \\
DELL PC Optiplex 170L \& monitor & $(140 \mathrm{~W})(€ 0.16 / \mathrm{kW} \mathrm{hr}) / 1000$ & 0.0224 \\
CompactRIO - control power & $(8.2 \mathrm{~W})(€ 0.16 / \mathrm{kW} \mathrm{hr}) / 1000$ & 0.0013 \\
D-link network switch & $(4.5 \mathrm{~W})(€ 0.16 / \mathrm{kW} \mathrm{hr}) / 1000$ & 0.0007 \\
BWD MiniLab - motion power & $(43 \mathrm{~W})(€ 0.16 / \mathrm{kW} \mathrm{hr}) / 1000$ & 0.0069 \\
Diode replacement & $(€ 11,410 / 10000 \mathrm{hr})$ & 1.141 \\
Maintenance labour & $(12 \mathrm{hr} / 2000 \mathrm{hr}$ operation $)(€ 50 / \mathrm{hr})$ & 0.3 \\
\multicolumn{2}{c}{ Total estimated micro-machining cost per hour } & $1.4723+0.064 \times \mathrm{P}$ \\
\hline
\end{tabular}

Micro-machining cost $[€ / \mathrm{m}]=\frac{1.4723+0.064 \times \mathrm{P} \frac{€}{\mathrm{hr}}}{(0.85) \times U\left[\frac{\mathrm{mm}}{\mathrm{sec}}\right]\left[3600 \frac{\mathrm{sec}}{\mathrm{hr}}\right]\left[\frac{\mathrm{m}}{1000 \mathrm{~mm}}\right]}=\frac{(0.481+0.021 \mathrm{P})}{\mathrm{U}}$ 


\section{Results and discussion}

\subsection{Experimental results}

The width values of the all 32 produced micro-channels were measured, at three different locations along the micro-channel, using an optical microscope with a high numerical aperture to ensure a high degree of accuracy of the measurement data. This procedure was repeated for three different locations along the channel axis and the average width was calculated. A Two Factorial Interaction (2FI) model was chosen for the width response and a quadratic model for the cost response. Table 4 shows the actual versus predicted value of the investigated combinations of the control parameters.

Table 4: Experimental measured and calculated responses vs predicted from the width and cost models.

\begin{tabular}{|c|c|c|c|c|c|c|c|c|c|}
\hline \multirow{2}{*}{$\begin{array}{c}\text { Exp. } \\
\text { No. }\end{array}$} & \multicolumn{2}{|c|}{ Width $(\mu \mathrm{m})$} & \multicolumn{2}{|c|}{ Cost $(€ / m)$} & \multirow{2}{*}{$\begin{array}{c}\text { Exp. } \\
\text { No. }\end{array}$} & \multicolumn{2}{|c|}{ Width $(\mu \mathrm{m})$} & \multicolumn{2}{|c|}{ Cost $(€ / m)$} \\
\hline & Actual & Predicted & Actual & Predicted & & Actual & Predicted & Actual & Predicted \\
\hline 1 & 116.0 & 105.9 & 0.991 & 0.993 & 17 & 89.0 & 96.5 & 0.289 & 0.289 \\
\hline 2 & 180.3 & 191.1 & 1.012 & 1.012 & 18 & 122.3 & 137.1 & 0.295 & 0.299 \\
\hline 3 & 263.2 & 276.4 & 1.033 & 1.031 & 19 & 65.2 & 80.2 & 0.165 & 0.167 \\
\hline 4 & 99.6 & 99.3 & 0.991 & 0.993 & 20 & 169.2 & 145.0 & 0.169 & 0.169 \\
\hline 5 & 152.9 & 167.4 & 1.012 & 1.012 & 21 & 211.2 & 209.8 & 0.172 & 0.170 \\
\hline 6 & 245.0 & 235.4 & 1.033 & 1.031 & 22 & 79.0 & 73.6 & 0.165 & 0.167 \\
\hline 7 & 80.9 & 75.5 & 0.991 & 0.993 & 23 & 118.4 & 121.2 & 0.169 & 0.169 \\
\hline 8 & 123.5 & 126.3 & 1.012 & 1.012 & 24 & 152.3 & 168.8 & 0.172 & 0.170 \\
\hline 9 & 193.0 & 177.2 & 1.033 & 1.031 & 25 & 50.8 & 49.8 & 0.165 & 0.167 \\
\hline 10 & 85.0 & 86.3 & 0.283 & 0.279 & 26 & 79.6 & 80.2 & 0.169 & 0.169 \\
\hline 11 & 163.5 & 161.3 & 0.289 & 0.289 & 27 & 113.4 & 110.6 & 0.172 & 0.170 \\
\hline 12 & 238.7 & 236.4 & 0.295 & 0.299 & 28 & 142.9 & 137.6 & 0.289 & 0.289 \\
\hline 13 & 72.7 & 79.8 & 0.283 & 0.279 & 29 & 142.9 & 137.6 & 0.289 & 0.289 \\
\hline 14 & 141.6 & 137.6 & 0.289 & 0.289 & 30 & 132.8 & 137.6 & 0.289 & 0.289 \\
\hline 15 & 207.4 & 195.4 & 0.295 & 0.299 & 31 & 138.5 & 137.6 & 0.289 & 0.289 \\
\hline 16 & 56.5 & 55.9 & 0.283 & 0.279 & 32 & 140.4 & 137.6 & 0.289 & 0.289 \\
\hline
\end{tabular}

\subsection{Analysis of variance (ANOVA)}

Analysis of variance (ANOVA) for the two models was carried out using Design-Expert software in order to test the significance of the regression models. The step-wise regression method was selected in order to eliminate the insignificant model terms automatically. The ANOVA for the two models summarises the analysis of each response in terms of sequential F-test, lack of fit test and show the significant model terms. Tables 5 and 6 show the ANOVA results for the width and cost models respectively. In addition they show the other adequacy measures $R^{2}$, adjusted $R^{2}$ and predicted $R^{2}$. All the adequacy measures are close to 1 and indicate significant relationships considering a significance threshold of 0.001 . The adequate precision ratios, being above four, in both models indicate adequate models discrimination. 
Table 5: ANOVA analysis for the width model.

\begin{tabular}{llllll}
\hline Source & Sum of Squares & d.f. & Mean Square & F Value & Prob > F \\
\hline Model & 93472.16 & 5 & 18694.43 & 141.7405 & $<0.0001$ \\
P & 60181.37 & 1 & 60181.37 & 456.293 & $<0.0001$ \\
PRF & 18902.16 & 1 & 18902.16 & 143.3155 & $<0.0001$ \\
U & 9581.894 & 1 & 9581.894 & 72.64958 & $<0.0001$ \\
P×PRF & 3550.08 & 1 & 3550.08 & 26.91658 & $<0.0001$ \\
P×U & 1256.653 & 1 & 1256.653 & 9.527901 & 0.0048 \\
Residual & 3429.191 & 26 & 131.8919 & & \\
Lack of Fit & 3355.696 & 21 & 159.795 & 10.87115 & 0.0074 \\
Pure Error & 73.495 & 5 & 14.699 & & \\
Corrected Total & 96901.35 & 31 & & & \\
\hline
\end{tabular}

$\mathrm{R}^{2}=0.965$, adjusted $\mathrm{R}^{2}=0.958$, predicted $\mathrm{R}^{2}=0.940$, adequate precision $=45.567$.

Analysis of variance indicated that for the width model the main effect of the laser power $(\mathrm{P})$, pulse repetition frequency (PRF), translation speed (U), the two level interaction of laser power and pulse repetition frequency $(\mathrm{P} \times \mathrm{PRF})$ and the two level interaction of laser power and translation speed $(\mathrm{P} \times \mathrm{U})$ are the most significant model terms associated with width. In the case of the cost model, the main effect of the laser power $(\mathrm{P})$, translation speed (U), the two level interaction of laser power and translation speed $(\mathrm{P} \times \mathrm{U})$ and the second order effect of translation speed $\left(\mathrm{U}^{2}\right)$ are the significant model terms.

Table 6: ANOVA analysis for the cost model.

\begin{tabular}{llllll}
\hline Source & \multicolumn{2}{l}{ Sum of Squares d.f. } & Mean Square & F Value & Prob $>$ F \\
\hline Model & 3.917822 & 4 & 0.979456 & 167972.2 & $<0.0001$ \\
$\mathrm{P}$ & 0.001875 & 1 & 0.001875 & 321.4944 & $<0.0001$ \\
$\mathrm{U}$ & 3.200602 & 1 & 3.200602 & 548888.9 & $<0.0001$ \\
$\mathrm{P} \times \mathrm{U}$ & 0.000926 & 1 & 0.000926 & 158.76 & $<0.0001$ \\
$\mathrm{U}^{2}$ & 0.71442 & 1 & 0.71442 & 122519.8 & $<0.0001$ \\
Residual & 0.000157 & 27 & $5.83 \mathrm{E}-06$ & & \\
Lack of Fit & 0.000157 & 22 & $7.16 \mathrm{E}-06$ & & \\
Pure Error & 0 & 5 & 0 & & \\
Corrected Total & 3.91798 & 31 & & & \\
\hline
\end{tabular}

$\mathrm{R}^{2}=0.999$, adjusted $\mathrm{R}^{2}=0.999$, predicted $\mathrm{R}^{2}=0.999$, adequate precision $=904.922$.

\subsection{Development of experiential and mathematical models}

Constructing a mathematical model for laser micro-machining process is an important step for understanding its behaviour, performance and for optimising the process itself. The experiential models for micro-channels' width and micro-machining cost in terms of actual factors as established are shown below:

Width $=19.915+223.484 \times \mathrm{P}+0.199 \times \mathrm{PRF}-2.101 \times \mathrm{U}-3.440 \times \mathrm{P} \times \mathrm{PRF}-16.505 \times \mathrm{P} \times \mathrm{U}$

Cost $=1.429+0.045 \times \mathrm{P}-1.008 \times \mathrm{U}-0.0142 \times \mathrm{P} \times \mathrm{U}+0.196 \times \mathrm{U}^{2}$ 
While the following final mathematical models are in terms of coded factors:

Width $=136.49+57.82 \times \mathrm{P}-32.41 \times \mathrm{PRF}-23.07 \times \mathrm{U}-17.20 \times \mathrm{P} \times \mathrm{PRF}-10.23 \times \mathrm{P} \times \mathrm{U}$

Cost $=0.29+0.010 \times \mathrm{P}-0.42 \times \mathrm{U}-0.008 \times \mathrm{P} \times \mathrm{U}+0.30 \times \mathrm{U}^{2}$

\subsection{Interaction effects of control parameters on the responses}

Fig. 3 (a) \& (b) show the interactive effect between translation speed, U, and laser power, P; while $\mathrm{PRF}=23 \mathrm{kHz}$ on the micro-channels' width and cost respectively. These two 3D graphs show that increased laser power increases the micro-channel width while having negligible effect on process cost. To a smaller extent an increase in speed resulted in a decrease in channel size while have a significant effect on process cost. This graph demonstrates that the micro-machining cost significantly decreases by increasing the sample translation speed and insignificantly increases by increasing the laser power. The effect of processing pulse repetition frequency on channel width was similar to that of laser power, seen in Figure 3 (a). PFR on the other hand had no effect on microchannel cost.
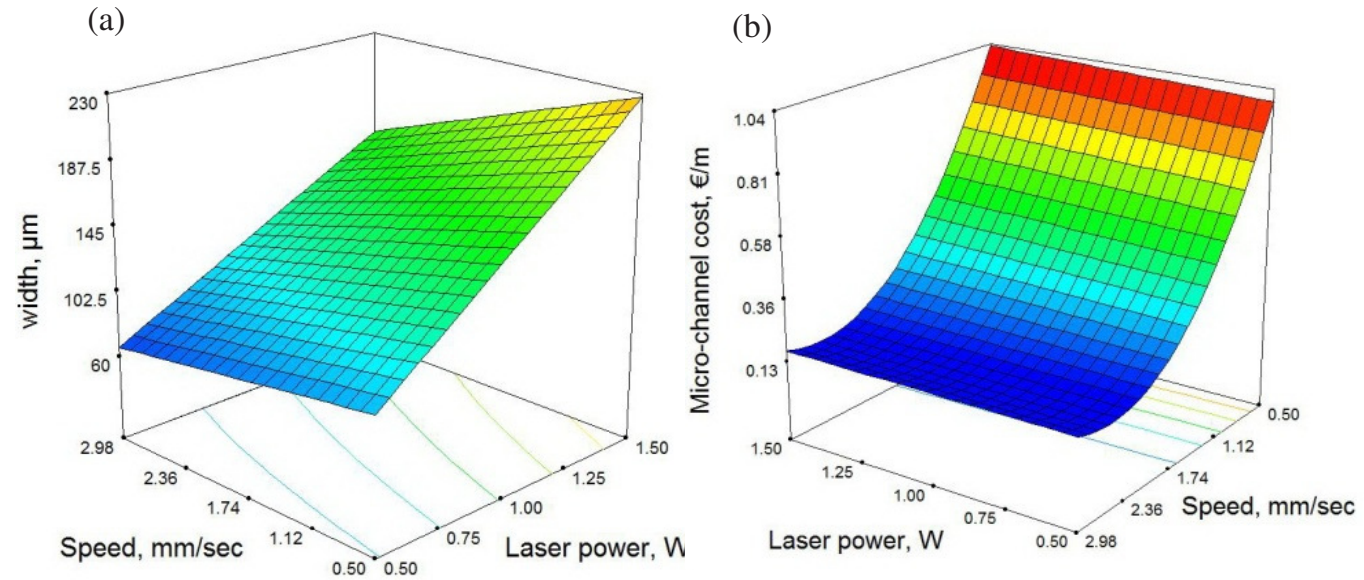

Fig. 3: Interactive effect (a) on width level for $U$ and $P$ with $P F R=23 \mathrm{kHz}$ and (b) on micro-machining cost for $\mathrm{P}$ and $\mathrm{U}$ with $\mathrm{PRF}=23 \mathrm{kHz}$.

\section{Conclusion}

From this work and within the parameters' limits investigated, several conclusions were reached.

1. $3^{3}$ factorial Design of Experiments (DoE) can be utilised as a prediction tool for laser micromachining process by constructing experiential and mathematical models which can be used for optimisation. The developed models using Response Surface Methodology (RSM) are efficient predictive tools for selection of laser micro-machining parameters

2. Micro-channels of predetermined geometry and least cost can be attained by using the developed models to estimate the work input process parameters.

3. Laser power is the most effective parameter in determining micro-channels width, the pulse repetition frequency has less effect and the translation speed of the work piece has the least effect.

4. Translation speed is inversely proportional to micro-machining cost. Moreover, it has a crucial role in determining the operating cost, while laser power has an insignificant effect on the cost and the pulse repetition frequency has no effect at all. 


\section{References}

1. J. Hecht, The Laser Guidebook, McGraw-Hill, 1986.

2. N.B. Dahotre and S. Harimkar, Laser Fabrication and Machining of Materials, Springer, 2008, pp. 247-288, ISBN978-0-387-72343-3.

3. A. Issa, Computational control of laser systems for micro-machining, PhD Thesis, Dublin City University, Ireland, 2007.

4. S. Juodkazis, K. Yamasaki, A. Marcinkevicius, V. Mizeikis, S. Matsuo, H. Misawa and T. Lippert, Micro-structuring of silica and polymethylmethacrylate glasses by femtosecond irradiation for Materials Science of MEMS applications, Mat. Res. Soc. Symp. Proc., Vol. 687, 2002, pp. B5.25.1 - B5.25.6.

5. S.C. Wang, C.Y. Lee and H.P. Chen, Thermoplastic microchannel fabrication using carbon dioxide laser ablation, Journal of Chromatography A, Vol. 1111, 2006, pp. 252 - 257.

6. F.G. Bachmann, Industrial laser applications, Applied Surface Science, Vol. 46, 1990, pp. 254 $-263$.

7. M.C. Gower, Industrial applications of laser micro-machining, Optical Society of America, 2000, pp. 56-67.

8. M. Goretty Alonso-Amigo, Polymer Micro-fabrication for Microarrays, Micro-reactors and Micro-fluidics, Journal of the Association for Laboratory Automation, Vol. 5, Issue 6, December-2000, pp. 96-101.

9. M. Kamata, M. Obara, R. Gattass, L. Cerami and E. Mazur, Optical vibration sensor fabricated by femtosecond laser micro-machining, Applied Physics Letters, Vol. 87, 2005, pp. 1-3.

10. J.H. Strickler and W.W. Webb, Three-dimensional optical data storage in refractive media by two-photon point excitation, Optical Letters, Vol. 16, 1991, pp. 1780 - 1782.

11. M.H. Hong, B. Luk'yanchuk, S.M. Huang, T.S. Ong, L.H. Van and T.C. Chong, Femtosecond laser application for high capacity optical data storage. Applied Physics A: Materials Science \& Processing, Vol. 79, Springer, 2004, pp. 791-794.

12. E.N. Glezer, M. Milosavljevic, L. Huang, R.J. Finlay, T.H. Her, J.P. Callan and E. Mazur, Three-dimensional optical storage inside transparent materials, Opt. Lett. Vol 21, 1996, pp. 2023-2025.

13. C.B. Schaffer, N. Nishimura and E. Mazur, Thresholds for femtosecond laser-induced breakdown in bulk transparent solids and water, Proceedings of SPIE, Vol. 3451, Time Structure of X-Ray Sources and Its Applications, San Diego, CA, 1998, pp. 2 - 8.

14. Karazi, S., A. Issa, and D. Brabazon, Comparison of ANN and DoE for the prediction of lasermachined micro-channel dimensions. Optics and Lasers in Engineering, 2009.

15. C.B. Schaffer, E.N. Glezer, N. Nishimura and E. Mazur, Ultrafast laser induced microexplosions: explosive dynamics and sub-micrometer structures, Photonics West, San Jose, 1998, pp. $36-45$.

16. A. Vaidyanathan, T. W. Walker, A. H. Guenther, The relative roles of avalanche multiplication and multiphoton absorption in laser-induced damage of dielectrics, IEEE Journal of Quantum Electronics, QE-16 (1980) 89-93.

17. Y.-I. Lee, K. Song, J. Sneddon, Laser-induced breakdown spectrometry, Nova Science publishers, Inc., New York, 2000.

18. Benyounis, K., A. Olabi, and M. Hashmi, Mechanical properties, weld bead and cost universal approach for $\mathrm{CO} 2$ laser welding process optimisation. International Journal of Computational Materials Science and Surface Engineering, 2009. 2(1): p. 99-109. 